\title{
Componentes Macroeconômicos e Estruturais da Crise Brasileira: o Subdesenvolvimento Revisitado
}

\author{
Pedro Rossi* \\ Guilherme Mello ${ }^{\dagger}$
}

\begin{abstract}
Resumo
O objetivo desse ensaio é elaborar um diagnóstico sobre a desaceleração da economia brasileira a partir dos seus elementos macroeconômicos e estruturais. Argumenta-se que os erros na condução da política econômica, presentes na maioria dos diagnósticos sobre a desaceleração, devem ser considerados no âmbito de condicionantes estruturais que caracterizaram o ciclo de crescimento da economia brasileira nos anos recentes. Esse ciclo amenizou características típicas do subdesenvolvimento apontadas por Furtado: i) ao modernizar os padrões de consumo de uma parcela importante da população; e, ii) ao melhorar qualitativamente 0 mercado de trabalho, reduzindo 0 desemprego e a informalidade. No entanto, o modelo de crescimento não logrou: i) modernizar a estrutura produtiva de forma a sustentar as transformações do lado da demanda; e, ii) incluir a mão de obra em setores de maior produtividade. Nesse sentido, o ciclo de crescimento que marcou os governos do Partido dos Trabalhadores (PT) não superou entraves estruturais, apenas reconfigurou alguns aspectos do nosso subdesenvolvimento.
\end{abstract}

Palavras-chave: Furtado, estruturalismo, consumo de massa, Dilma, Lula

JEL Classification: N16, 011, 020

\section{Apresentação}

Os governos do Partido dos Trabalhadores (PT) se encerram de forma dramática, com forte retração da atividade econômica em 2015 após alguns anos de desaceleração. Em um contexto de crise política e institucional, os diagnósticos em torno da desaceleração e da queda do PIB nos anos recentes ainda são prejudicados pela falta de distanciamento histórico e por uma acirrada disputa política pela narrativa econômica. Reconhecendo essas limitações, esse ensaio busca contribuir para o debate sobre os diagnósticos da desaceleração econômica no Brasil, incorporando elementos da literatura estruturalista do desenvolvimento ao debate macroeconômico.

Para isso, este trabalho se divide em duas partes, além desta apresentação. A primeira busca resgatar alguns dos principais diagnósticos presentes no debate público e acadêmico acerca da desaceleração que, em geral, enfatizam os erros na condução da política macroeconômica. A segunda parte resgata elementos da literatura estruturalista do desenvolvimento, introduzindo uma análise acerca das mudanças nas estruturas de demanda e produtiva ocorridas no período, que ajudam a explicar as dificuldades de manutenção do crescimento econômico. Por fim, as considerações finais buscam articular as relações entre a macroeconomia e os desafios estruturais, e argumentar que a economia brasileira mantem características típicas do subdesenvolvimento.

\footnotetext{
* Professor do Instituto de Economia da Unicamp. pedrolrossi@gmail.com

${ }^{\dagger}$ Professor do Instituto de Economia da Unicamp. guil.mello@gmail.com
} 


\section{A desaceleração econômica: a política macro no centro do diagnóstico}

O governo Dilma foi alvo de diferentes diagnósticos que buscam explicar a desaceleração econômica verificada no período de seu primeiro mandato, assim como a recessão a partir de 2015. Esses diagnósticos refletem posições teóricas diversas, além de ênfases variadas acerca da importância das políticas econômicas. Em linhas gerais, identificamos quatro ênfases interpretativas sobre o período em questão.

A primeira atribui a desaceleração econômica no primeiro governo Dilma às políticas econômicas "heterodoxas" ${ }^{1}$. Nesta interpretação, a base da política econômica teria sofrido uma inflexão em seu eixo orientador anterior, o chamado tripé-macroeconômico, passando a adotar políticas macro voltadas para a promoção do crescimento da demanda doméstica. Esta nova forma de conduzir a política econômica foi denominada de "nova matriz econômica" (NME) que constituiu uma nova forma de gestão da política econômica, incompatível com as regras que orientam o tripé tradicional (Barbosa, 2015; M esquita, 2014)2.

Segundo estes autores, a desaceleração e posterior retração da economia brasileira seria 0 resultado da adoção da NME, que se mostrou incapaz de promover o crescimento e a melhoria da produtividade, gerando apenas pressões inflacionárias e deterioração fiscal. Sua reversão e a retomada da velha gestão do chamado "tripé", que ocorre de fato a partir de 2015 - assim como o forte ajuste fiscal - é defendida pelos autores desta corrente como forma de trazer a inflação para o centro da meta, retomar a confiança ${ }^{3}$ e o crescimento da produtividade abalada pela adoção de políticas intervencionistas ${ }^{4}$.

$\mathrm{Na}$ contramão desse diagnostico, diversos autores buscam enfatizar outros fatores para explicar a situação econômica do período. Estas interpretações também apontam problemas na condução da política macroeconômica doméstica, mas de natureza bastante distinta. Alguns apontam a sobrevalorização cambial como elemento central que explica a deterioração da estrutura produtiva brasileira e a consequente desaceleração econômica ${ }^{5}$. Embasada na abordagem novo desenvolvimentista, essa interpretação também aponta a valorização salarial acima dos ganhos de produtividade como um problema a ser enfrentado, defendendo uma regra de crescimento salarial em linha com o aumento da produtividade, não

\footnotetext{
1 "Parte da desaceleração recente pode ser atribuída à alteração do regime de política econômica adotado a partir de 2009. A alteração não ocorreu em função de haver na sociedade forte apoio por este curso de política econômica. As políticas foram adotadas por que os policy makers do momento acreditam que estas são as políticas mais adequadas para acelerar o crescimento. Podem, portanto, serem revertidas" (Barbosa e Pessoa, 2014, p. 1)

2 "A NME caracterizou-se por uma política fiscal expansionista, pelo abandono do Banco Central do protocolo do regime de metas de inflação fixando taxas de juros baixas incompatíveis com a meta de inflação, expansão do crédito pelos bancos estatais, intervenção sistemática do Banco Central (Bacen) no mercado de câmbio deixando de lado o sistema de câmbio flexível. Ademais, introduziu-se controle de preços nos produtos derivados do petróleo e com a renovação dos contratos de concessão de energia elétrica desejava-se reduzir as tarifas de eletricidade" (Barbosa, 2015)

3 “(...) A destruição do tripé macroeconômico tirou a capacidade dos agentes em construir cenários futuros para a economia" (Barbosa e Pessoa, 2014, p. 4).

4 "Uma possível conjectura é que o enorme intervencionismo do setor público que se iniciou de forma mais pesada em 2009 tenha reduzido muito a produtividade incremental do capital em função, provavelmente de má alocação do recurso" (Barbosa e Pessoa, 2014, p. 4).

5 “(...) a principal causa do fracasso do período desenvolvimentista social não foram os déficits públicos elevados (o governo errou nesse ponto apenas em 2013 e 2014), mas o câmbio apreciado no longo prazo - uma política igualmente populista. Durante o governo Lula a apreciação do real foi brutal, e inviabilizou o governo Dilma" (Bresser, 2016)
} 
pressionando dessa forma as margens de rentabilidade do setor industrial (Bresser, Oreiro e Marconi, 2016).

Outra interpretação enfatiza a contração fiscal e monetária como fator chave para a desaceleração. Para Serrano e Summa (2012, 2014 e 2015), o governo Dilma I se inicia com uma estratégia de política econômica ao promover a desaceleração econômica por meio de políticas fiscais e monetárias restritivas. Esta estratégia, que os autores denominam "desaceleração rudimentar", teria provocado efeitos recessivos e se configurou como a principal causa da desaceleração posterior, uma vez que se desarticula uma série de investimentos que estavam programados antes da imposição deste "freio" na economia ${ }^{6}$.

Já outros autores enfatizam o fracasso de uma agenda de políticas econômicas voltadas a estimular a oferta agregada, chamada de estratégia "industrialista" ${ }^{7}$, que constitui uma tentativa de responder à deterioração estrutural do complexo industrial brasileiro e às pressões políticas das entidades empresariais (Rossi e Biancarelli, 2015). Essa estratégia teria tido início já no final de 2011, quando o governo percebe que a desaceleração econômica começava a prejudicar as perspectivas de crescimento ${ }^{8}$.

No centro das políticas industrialistas está a queda de rentabilidade das empresas industriais como problema a ser enfrentado ${ }^{9}$. Desta forma, a agenda central do governo passa a ser a de garantir condições de competitividade para a indústria nacional em meio a um cenário internacional adverso, reduzindo custos de insumos (como os custos de energia elétrica e combustível), de crédito (ao reduzir os juros - em um primeiro momento - e o spread bancário), desvalorizando a taxa de câmbio e com uma ampla política de subsídios e desonerações fiscais.

No entanto, ao invés de estimular a atividade econômica, a maior parte das medidas pode ter servido apenas para proteger as empresas da queda na taxa de rentabilidade que vinham experimentando, mitigando os efeitos de aumento de custos e da concorrência externa $^{10}$. Além do aumento da concorrência externa causada pela crise internacional, as

\footnotetext{
6 "A análise dos dados da economia brasileira mostra que a política macroeconômica interna tanto monetária quanto fiscal, foi responsável por uma boa parte da forte desaceleração do crescimento do produto no Brasil a partir de 2011" (Serrano e Summa, 2012).

7 Importante ressaltar que a agenda "industrialista" não é necessariamente industrializante. Apesar de seu objetivo ser este, o termo industrialista diz respeito aos interesses dos industriais ao redor da construção e implementação desta agenda, não de seus efeitos reais.

${ }^{8}$ Aqui cabe um debate sobre se a estratégia da "desaceleração rudimentar" não era já um prenúncio, uma preparação para a posterior estratégia industrialista posterior. Ao abrir "espaço fiscal" (aumentando o primário), o governo estaria tanto colaborando para a redução mais veloz dos juros (M ello e Chilliatto-Leite, 2011), quanto ganhando margem de manobra para realizar as desonerações fiscais, marcas posteriores da estratégia industrialista.

9 " Dilma's first term was marked by a policy shift aiming precisely at raising profit margins, which happened through the reduction of the policy rate and the interest rate spreads, the devaluation of the exchange rate, and cuts in payroll taxes and energy prices" (Carvalho e Rugitski, 2015, p. 14).

${ }^{10}$ Para Hiratuka e Sarti (2015), a partir da crise internacional de 2008, com o lento crescimento da demanda global e 0 aumento da capacidade ociosa, cria-se um ambiente de concorrência acirrada onde a indústria brasileira tem dificuldade de enfrentar uma competição em custo bastante acirrada, liderada pela produção chinesa, mas que envolve outros produtores asiáticos e outras empresas líderes dos oligopólios globais.
} 
empresas brasileiras se viam diante da desaceleração da demanda doméstica e da redução de sua rentabilidade ${ }^{11}$.

Neste cenário, a queda cíclica da demanda interna e a redução do investimento público apenas colaboraram para reduzir ainda mais as perspectivas de crescimento destas empresas, que se utilizaram dos benefícios fiscais do governo para recompor parcialmente suas margens de rentabilidade (Bastos, 2015) ${ }^{12}$. 0 fracasso do industrialismo como estratégia de desenvolvimento econômico pode ser explicado, portanto, tanto por fatores conjunturais (como a crise política a partir de junho de 2013 e mudanças nas condições da economia global), como por fatores estruturais, abordados na sessão II deste artigo.

Em síntese esses diagnósticos sobre a desaceleração ressaltam os equívocos da política econômica; seja a flexibilização da matriz macroeconômica e o excesso de intervencionismo Estatal, seja o desalinhamento cambial, seja a contração da demanda pública ou as políticas de oferta voltadas para a indústria. Contudo, para além da gestão macroeconômica pode-se apontar que a crise brasileira é reflexo de entraves estruturais típicos do subdesenvolvimento que não foram superados. Em certo sentido, a condução errática da política macro nos governos Dilma Rousseff deve ser contextualizada como uma tentativa (fracassada) de contornar os efeitos desses entraves estruturais que permeiam e condicionam 0 desenvolvimento brasileiro. Nesse contexto, a próxima seção busca mostrar que nos governos do PT a economia brasileira passou por um processo de modernização e massificação dos padrões de consumo sem, contudo, modernizar a estrutura produtiva, a ponto de dar sustentabilidade ao processo de desenvolvimento.

\section{Componentes estruturais da desaceleração econômica: o subdesenvolvimento revisitado}

\subsection{Furtado e o subdesenvolvimento}

Para Furtado (1971), o subdesenvolvimento é a manifestação de uma inserção subordinada no capitalismo internacional, que tende a se perpetuar sobre formas cambiantes, produzindo má distribuição de renda e a coexistência de setores modernos da economia com setores de baixa produtividade, que abrigam o subemprego e a informalidade ${ }^{13}$. Ainda segundo Furtado, uma das principais características responsáveis pelo subdesenvolvimento é a modernização dos padrões de consumo restrita a uma parcela mais rica da população (Furtado, 1992). Ou seja, a assimilação do progresso técnico pelo lado da demanda de bens finais de consumo por uma parcela ínfima da demanda agregada conduz a uma conformação estrutural que bloqueia a passagem do crescimento ao desenvolvimento:

"Subdesenvolvimento é um desequilíbrio na assimilação dos avanços tecnológicos produzidos pelo capitalismo industrial a favor das inovações que incidem diretamente

\footnotetext{
${ }^{11}$ Sobre a saúde financeira das empresas brasileiras, ver Almeida et. ali (2016) e Rezende (2016). Em uma análise minskiana, Rezende trata a deterioração do balanço das empresas no Brasil como parte da causa da desaceleração e crise da economia.

12 “(...) a mudança de preços relativos pode ter aumentado margens de lucro (ou, pelo menos, mitigado a pressão sobre as margens em virtude do encarecimento de insumos importados), mas claramente não teve sucesso em induzir, em termos agregados, a produção e o investimento privado na indústria de transformação." (Bastos, 2015, p. 279)

${ }^{13}$ Segundo Bielchowsky (2007), Furtado recupera a discussão de Lewis (1954) e introduz no arcabouço analítico estruturalista a discussão sobre a dificuldade que os setores urbanos modernos têm para absorver a força de trabalho subempregada. Dada essa dificuldade, a persistência do subemprego explica a coexistência de aumentos de produtividade e salários em baixos níveis no longo prazo.
} 
sobre o estilo de vida. Essa proclividade à absorção de inovações nos padrões de consumo tem como contrapartida atraso na adoção de métodos produtivos mais eficazes. É que os dois processos de penetração de novas técnicas se apoiam no mesmo vetor que é a acumulação. Nas economias desenvolvidas existe um paralelismo entre a acumulação nas forcas produtivas e diretamente nos objetos de consumo. 0 crescimento de uma requer 0 avanço de outra. A raiz do subdesenvolvimento reside na desarticulação entre esses dois processos causada pela modernização". (Furtado, 1992, p. 8)

Nesse contexto, Furtado (1992) argumenta que a concentração de renda e a estreiteza do mercado de consumo doméstico são fatores que limitam a escala das empresas e 0 desenvolvimento da estrutura produtiva. Apesar das criticas aos desdobramentos dessa tese ${ }^{14}$, Furtado inspirou o debate em torno da distribuição de renda como elemento fundamental de um modelo de desenvolvimento.

\subsection{Mercado de consumo de massa no centro do modelo econômico}

Segundo Bielschowsky (2014), a constituição de um mercado de consumo de massas era uma estratégia econômica deliberada dos governos do Partido de Trabalhadores e foi explicitada no programa de governo do partido em 2002 e nos planos plurianuais (PPA) elaborados ao longo do governo Lula. Nessa estratégia, a formação do mercado de consumo de massa se sustenta em dois pilares: o primeiro é a distribuição de renda que, por sua vez, é promovida por políticas de transferências e aumento de salários; já o segundo pilar é o estímulo à inclusão bancária e ao crédito para as famílias. Uma vez constituído, esse mercado teria a capacidade de estimular a estrutura produtiva doméstica de forma a atender a ampliação da demanda e, por meio de ganhos de escala das empresas domésticas, proporcionar aumentos produtividade e crescimento econômico (Bielschowsky, 2014).

Como pôde ser observado, a estratégia de desenvolvimento de um mercado de consumo de massa não ficou apenas no papel. Houve uma intencionalidade política que se verificou:

1) Na política de aumento do salário mínimo, que apresentou crescimento real de $70 \%$ ao longo dos governos petistas, elevando os rendimentos do trabalho e contribuindo para a redução da desigualdade ${ }^{15}$.

2) Nas políticas de transferências de renda, tanto com o aumento do valor dos benefícios da previdência e seguridade social (em grande medida vinculados ao salário mínimo), quanto com a criação de programas de transferência como bolsa família ${ }^{16}$.

\footnotetext{
${ }^{14}$ Tavares e Serra (1973) criticam a tese de Furtado de que a má distribuição estrutural de renda gera uma tendência à estagnação do crescimento econômico. Esses argumentam que a acumulação capitalista pode acontecer a despeito de um mercado consumidor limitado e de um grande contingente da população marginalizado.

${ }^{15}$ De acordo com Hoffman (2013), por representar a maior parte da renda declarada, a melhoria salarial foi o fator mais importante para explicar a redução do GINI no período, respondendo por aproximadamente $40 \%$ da melhoria do indicador.

${ }^{16}$ O programa bolsa família contemplou 14 milhões de famílias em 2012, segundo o Relatório de Informações Sociais, M inistério do Desenvolvimento Social e Combate à Fome, e contribuiu com $16 \%$ da melhoria do GINI entre 2001 e 2011 (Hoffman, 2013), mesmo representando menos de 1\% da renda total declarada.
} 
3) Nas políticas de facilitação do credito às famílias e empresas, dentre as quais se destacam o crédito consignado, 0 crédito habitacional e a expansão do crédito dos bancos públicos em particular após a crise de $2008^{17}$.

4) No aumento do volume de despesas públicas na área social, que passaram de $21,9 \%$ em 2005 para 25,2\% do PIB em 2010, que possuem um elevado multiplicador e contribuem para geração de empregos formais e informais (Castro, 2012).

\subsection{Transformações na demanda e no mercado de trabalho}

O impacto destas políticas se concretizou na redução da pobreza e da miséria, além da desigualdade de renda medida pelo índice de GINI, que passou de 0,593 para 0,526 entre 2001 e $2012^{18}$. De acordo com Castro (2012), a proporção da população que vive com menos de meio salário mínimo por mês passou de 46,6\% em 2003 para 29,2\% em 2009. Segundo Quadros (2015), entre os anos de 2002 e 2013 observou-se uma queda expressiva no número de miseráveis, saindo de 45 para 16 milhões de pessoas, com um aumento expressivo dos extratos médio (a baixa classe média, por exemplo, passou de 54 milhões de pessoas em 2002 para 89 milhões em 2013). Para além do aumento da renda da população mais pobre, 0 mercado de crédito também incluiu uma parte importante da população. 0 crédito para pessoas físicas cresceu a taxas elevadas entre 2008 e 2013, ampliando-se de R\$ 712 milhões para $\mathrm{R} \$ 1,464$ bilhões em 2013 (Dieese, 2014).

Com o aumento da renda e do crédito, o consumo de bens duráveis saltou, fazendo com que a parcela da população com acesso a um conjunto de bens duráveis (telefone, televisão, fogão, geladeira, rádio e máquina de lavar) subisse de 28,2\% em 2003 para 44,4\% em 2012 (IPEA, 2013). Dessa forma, nesse período verificou-se uma democratização do acesso aos bens de consumo duráveis e uma ampla modernização do padrão de consumo da população brasileira. Essa nova configuração da demanda teve grande impacto no mercado de trabalho, no qual se observa uma atenuação das características clássicas do subdesenvolvimento apontadas por Furtado.

Observou-se também uma queda significativa na taxa de desemprego e aumento do emprego formal. A taxa de desemprego caiu de 12\% em 2002 para próxima de 5\% em 2014 (segundo dados da antiga PME-IBGE), o que juntamente ao crescimento do emprego formal (que cresceu dez pontos percentuais, alcançando $63 \%$ da força de trabalho) e ao aumento do salário médio real (crescimento de $17 \%$ no mesmo período) ajuda a explicar a melhoria nos indicadores sociais (Komatsu e Menezes Filho, 2015). No entanto, essa reconfiguração do mercado de trabalho beneficiou principalmente o emprego no setor de serviços, que cresceu

\footnotetext{
${ }^{17}$ Essas medidas, em conjunto com o aumento da renda e do emprego, foram responsáveis pelo aumento da relação crédito/PIB de 23,8\% em 2003 para 55,8\% em 2014, com destaque para 0 crescimento do crédito direcionado (que passa de $32 \%$ de participação relativa no saldo total de crédito em 2008 para 44\% em 2013), em particular o crédito consignado (crescimento de 128,9\% entre janeiro de 2008 e dezembro de 2013) e o crédito imobiliário total (crescimento de $474,8 \%$ no mesmo período). (Dieese, 2014)

${ }^{18}$ É importante ressaltar, no entanto, que recentes estudos com bases da declaração de Impostos de Renda tendem a minimizar a distribuição de renda no período, confirmando uma melhoria na distribuição de renda do trabalho, mas apontando certa estabilidade na distribuição da renda total, como fruto dos elevados rendimentos do capital (Medeiros et. al., 2015). Da mesma forma, Dedecca (2014) mostra que a participação dos 1\% mais ricos na renda total permaneceu inalterada, havendo apenas redistribuição entre as camadas intermediárias. Essa melhoria na estratificação social, tampouco significou uma melhor distribuição da riqueza, conforme apontam Carvalho e Rugitsky (2015), indicando a necessidade de maiores estudos sobre 0 tema.
} 
41,5 \% entre 2004 e 2013, representando 79,6\% das oportunidades ocupacionais não agrícolas criadas no período (Baltar e Leone, 2015).

\subsection{Transformações na estrutura produtiva}

Concomitantemente, as profundas mudanças na estrutura de demanda e no mercado de trabalho também foram acompanhadas de transformações do lado da oferta. No entanto, essas transformações não promoveram mudanças que pudessem superar entraves estruturais ao desenvolvimento. Segundo Bielschowsky et. al. (2014b), o investimento, medido pela formação bruta de capital fixo, em setores ligados ao mercado de consumo de massa teve forte alta nos anos de mais forte expansão da economia brasileira (2005-2008), com média de expansão de 13,2\% ao ano, superior à taxa media de crescimento do investimento agregado, de $12,4 \%$ ao ano. No entanto, essa expansão ocorreu principalmente no setor de serviços $(14,4 \%$ ao ano) e no setor de consumo de não duráveis ( $12,9 \%$ ao ano), enquanto que 0 investimento no setor de bens de consumo de duráveis foi próximo de zero $(-0,1 \%$ ao ano).

Segundo os autores, no triênio 2006-2008 a produção interna cobriu apenas 50,6\% da variação da demanda de consumo de bens duráveis, sendo $36,1 \%$ atendida por aumento de importações e 13,3\% por queda nas exportações. Nesses mesmos setores industriais, 0 coeficiente importado aumenta de 8,1\% em 2005 para 17,3\% em 2008 e o coeficiente exportado, de $12,8 \%$ para $9,3 \%$ (Bielschowsky et. al, 2014). Nesse sentido, no que se refere ao setor de produção de bens duráveis, o consumo de massas no Brasil não gerou o dinamismo esperado na oferta de produtos domésticos.

Portanto, o ciclo de crescimento dos governos Lula foi caracterizado pela ampla modernização da estrutura de demanda sem uma equivalente modernização na estrutura produtiva capaz de supri-la. Como apontado por Nogueira, Infante e Mussi (2014), a partir da analise da produtividade dos setores de atividade entre 2000 e 2009, a estrutura produtiva se manteve praticamente tão heterogênea quanto, historicamente, sempre foi no país.

\subsection{Relaxamento da restrição externa e contradições no modelo}

Como destacado por Medeiros (2015), o ciclo de crescimento brasileiro foi viabilizado graças ao relaxamento da restrição externa por conta de dois fatores principais: a melhora expressiva dos termos de troca e a forte entrada de capitais estrangeiros no âmbito de uma expansão da liquidez global antes e depois da crise de $2008^{19}$.

Em relação ao primeiro fator, a melhora nos termos de troca jogou um papel duplo e contraditório no desenvolvimento brasileiro recente: por um lado, contribui para a formação do mercado de consumo de massa por meio do barateamento dos bens industriais e da disponibilidade de divisas para importação dos mesmos, por outro lado, essa melhora nos termos de troca reforçou a reprimarizacão da pauta exportadora. Entre 2007 e 2010, a participação dos produtos primários saltou 10 pontos percentuais, alcançando $51 \%$ das exportações brasileiras (De Negri e Alvarenga, 2011) enquanto que a pauta importadora mostrou uma composição relativamente estável no mesmo período, no qual a parcela dos

\footnotetext{
19 "Na última década, o relaxamento da restrição externa decorrente da demanda de commodities, da mudança nos termos de troca e da liquidez internacional viabilizou no país - como em geral nos países exportadores de commodities - maior crescimento e redução da pobreza e das desigualdades da renda. Com a elevação do salário mínimo, das transferências de renda e da expansão do crédito houve grande massificação dos padrões de consumo e forte penetração das importações." (M edeiros, 2015, p. 168)
} 
bens industriais correspondeu em torno de $40 \%$ das importações, a despeito da queda relativa dos preços de bens industriais e do aumento relativo do quantum de produtos industriais importados (Dos Santos, et. al. 2015). Nesse sentido, não houve uma melhora na composição do comércio externo, considerada como elemento central por Furtado (1971) e Pinto (1979), pelo contrário, a assimetria entre a pauta importadora e exportadora é reforçada.

Disso, destaca-se uma contradição importante do modelo: o barateamento dos bens industriais importados e o excedente produtivo do setor primário foram funcionais à sustentação do mercado de consumo de massa, mas, ao mesmo tempo, contribuíram para a deterioração na pauta de comércio externo e na estrutura produtiva.

\subsection{Abertura financeira e instabilidade macroeconômica.}

O movimento das moedas periféricas diante do ciclo de liquidez pode ser apontado como um fenômeno contemporâneo do subdesenvolvimento, adequado ao contexto de liberalização e abertura financeira. No capitalismo contemporâneo, países com moedas periféricas e ampla abertura financeira estão sujeitos à uma instabilidade macroeconômica que se transmite da volatilidade dos fluxos capitais financeiros para os preços-chave da economia, como as taxas de câmbio e de juros (De Conti, Biancarelli e Rossi, 2013).

Em particular, a forte correlação negativa entre essas moedas com os preços de commodities, que também são condicionados pelo ciclo de liquidez, por um lado ameniza 0 impacto inflacionário da flutuação desses preços, mas, por outro lado, reforça a inserção dessas economias na velha divisão internacional do trabalho. Ou seja, enquanto a taxa de câmbio absorve os choques de preços de commodities, funcionando como um amortecedor de choques de preços para a economia doméstica, essa também se apresenta como um fator de aumento da incerteza para o empresário industrial, que tem dificuldade em formar expectativas de preço, risco e retorno.

Nesse contexto, a entrada de capitais externos estimulada pelos altos juros praticados no Brasil contribuiu para uma forte valorização cambial da taxa real-dólar ${ }^{20}$ que, por sua vez, contribuiu de forma importante para o funcionamento do mercado de consumo de massas ao reduzir os preços dos bens transacionáveis e amenizar as pressões inflacionarias decorrentes do processo redistributivo ${ }^{21}$. Concomitantemente aos efeitos positivos sobre o ciclo de consumo, a entrada de capitais externos, por meio da valorização cambial, produz efeitos sobre a estrutura industrial. Dentre eles a desconstrução de cadeias produtivas e 0 aumento do coeficiente de penetração das importações, que na indústria de transformação, por exemplo, passou de 10,2\% em 2003 para 17,6\% em 2014, com destaque para o crescimento da importação de insumos industriais, que passou de 16,5\% em 2003 para 25,8\% em $2014^{22}$.

Adicionalmente, a expressiva entrada de capitais estrangeiros possibilitou uma maior absorção de produtos importados, além de provocar efeitos diretos e indiretos sobre a estrutura produtiva. Em particular, 0 aumento dos investimentos diretos estrangeiros no Brasil foi expressivo, passando de US\$ 108 bilhões em março de 2003 para US\$ 660 bilhões em

\footnotetext{
${ }^{20}$ Em realidade, os ciclos de valorização cambial ocorrem menos por conta de fluxos de capitais e mais por causa da especulação com derivativos de câmbio, como mostra Rossi (2016).

${ }^{21}$ Entre 2004 e 2009, o aumento de preços de serviços pressionou 0 índice de inflação, mas foi compensado por uma baixa inflação de bens transacionáveis. Como mostra Summa (2014), a média nesse período da inflação de alimentos e industrializados foi respectivamente 4,9 e 3,9\%, e esteve abaixo do IPCA médio $(5,2 \%)$ e bastante inferior à inflação de serviços $(6,5 \%)$.

${ }^{22}$ Dados a preços constantes da CNI, disponível em Indicadores CNI - Estatísticas - Coeficiente de abertura comercial.
} 
março de $2015^{23}$. Se por um lado, esses investimentos podem propiciar transferências tecnológicas e modernização da estrutura produtiva doméstica, por outro, a desnacionalização crescente da estrutura produtiva condiciona as decisões de investimento às estratégias globais das multinacionais. Como assinalado por Pinto (1971), uma entrada excessiva de capitais externos provoca a "estrangeirização" e dependência tecnológica além "da alienação dos centros de decisão".

Nesse sentido, a contradição desse modelo de desenvolvimento é que vários dos fatores que contribuíram positivamente para constituição do mercado de consumo de massas também impactaram negativamente a estrutura produtiva, dentre eles a melhora nos termos de troca e a valorização cambial. Esses fatores davam sustentação ao ciclo de consumo e ao mesmo tempo mascaravam os desequilíbrios entre demanda e oferta doméstica.

\section{Considerações finais}

Nesse ensaio argumentou-se que, nos governos do Partido dos Trabalhadores, o ciclo de crescimento amenizou características típicas do subdesenvolvimento: (i) ao modernizar os padrões de consumo de uma parcela importante da população; e, (ii) ao melhorar qualitativamente 0 mercado de trabalho reduzindo o desemprego e a informalidade, em condições de relaxamento da restrição externa. No entanto, o modelo de crescimento não logrou: (i) modernizar a estrutura produtiva de forma a sustentar as transformações do lado da demanda; e, (ii) incluir a mão de obra em setores de maior produtividade. Nesse sentido, esse ciclo de crescimento não superou entraves estruturais, apenas reconfigurou alguns aspectos do subdesenvolvimento brasileiro.

No primeiro governo Dilma, com os efeitos da crise internacional, desmontam-se mecanismos de sustentação do ciclo de consumo, com a reversão dos termos de troca e a desvalorização cambial. Esperava-se que essa reversão, associadas às políticas industrialistas do governo, pudessem dar sustentação a um processo de melhora na estrutura produtiva. No entanto, não foi o que ocorreu. Ao contrário, à desaceleração do crescimento dos componentes da demanda somou-se uma deterioração da estrutura produtiva, impulsionada pelo aumento da concorrência externa e por uma disputa por mercados mais acirrada.

Portanto, para além dos erros na condução da política econômica, a desaceleração da economia brasileira deve ser entendida a partir dos elementos estruturais que constituíram a formação do mercado de consumo e da dificuldade da estrutura produtiva em acompanhar as transformações na demanda. Nesse sentido, a compatibilização de um projeto redistributivo precisa considerar as mudanças necessárias na estrutura produtiva para logra a superação dos entraves estruturais que condicionam o subdesenvolvimento brasileiro.

Por fim, nem os entraves estruturais tampouco os erros de política econômica no primeiro governo Dilma explicam a intensidade da queda da atividade econômica em 2015 e 2016. Essa crise deve ser entendida no contexto de uma crise política e de uma mudança radical na condução da política econômica, que promoveu uma forte contração fiscal e monetária, uma desvalorização cambial e um choque de preços administrados ${ }^{24}$.

\footnotetext{
${ }^{23}$ Segundo dados do Banco Central do Brasil.

${ }^{24}$ Para uma crítica às políticas do segundo governo Dilma ver Belluzzo e Bastos (2015) e Forum21, Plataforma Política Social, GT de M acro SEP (2016).
} 


\section{Referências}

Almeida, J. S. G. et al. (2016). "A fragilização financeira das empresas não financeiras no Brasil pós-crise", Texto para discussão IE-UNICAM P, n 281. Outubro de 2016.

Baltar, P. E. A.; Leone, E. T. (2015). "O emprego assalariado nos anos 2000: mudanças de composição e de renda por idade e sexo", Anais do XIV Encontro Nacional da ABET .

Barbosa, F. H. (2015). "Crises econômicas e política de 2015: origens e consequências", Revista Conjuntura Econômica, vol. 69, nro. 09, setembro de 2015.

Barbosa, F. H.; Pessoa, S. (2014). "Desaceleração recente da economia", In: Centro de Debates de Políticas Públicas, Sob a Luz do Sol, Uma Agenda para o Brasil: A Política Econômica do Governo Lula: a volta do experimentalismo, CDPP.

Bastos, P. P. Z. (2015). "Austeridade Permanente? A crise global do capitalismo neoliberal e as alternativas no Brasil", In: BELLUZZO, L. G.; BASTOS, P. P. Z. (org.) Austeridade para quem? Balanço e perspectivas do governo Dilma Rousseff, São Paulo: Carta Maior; Friedrich Ebert, 2015. 352 p.

Belluzzo, L. G.; Bastos, P. P. Z (2015). "Austeridade para Quem? Balanço e perspectivas do governo Dilma Rousseff", São Paulo: Carta M aior e Fundação Friedrich Ebert.

Bielschowsky, R. (2007). "As contribuições de Celso Furtado ao estruturalismo", In: SABOIA, J.; CARVALHO, F.C. (Orgs) Celso Furtado e o Século XXI, Rio de Janeiro: Manole.

Bielschowsky, R. (2014). "Estratégia de desenvolvimento e as três frentes de expansão no Brasil: um desenho conceitual", In: Calixtre, A.; Biancarelli, A.; Cintra, M. A.. (Org.). Presente e Futuro do Desenvolvimento Brasileiro. 1ed. Brasilia: IPEA, p. 195-225.

Bielschowsky, R. et. al. (2014b). "Evolução dos investimentos nas três frentes de expansão da economia brasileira na década de 2000", In: Calixtre, A.; Biancarelli, A.; Cintra, M. A. (Org.). Presente e Futuro do Desenvolvimento Brasileiro. 1ed.Brasilia: IPEA, p. 195-225.

Bielschowsky, R. (2016). "Onde foi que erramos? Quando e por que a economia saiu da rota". Folha de S. Paulo, Ilustríssima, São Paulo, 27 mar. 2016.

Bielschowsky, R.. Oreiro, J. L; M arconi, N. (2016). "Macroeconomia Desenvolvimentista: Teoria e Política Econômica do Novo-Desenvolvimentismo". Elsevier: Rio de Janeiro.

Carvalho, L.; Rugitsky, F. (2015). "Growth and distribution in Brazil the 21st century: revisiting the wage-led versusprofit-led debate", Departamento de Economia da FEA-USP, São Paulo, Working Paper series. $n^{\circ}$ 2015-25.

Castro, J. A. (2012). "Política social e desenvolvimento no Brasil", Economia e Sociedade, Campinas, v. 21, Número Especial, p. 1011-1042, dez. 2012.

DE Conti, B.; Biancarelli, A. M.; Rossi, P. (2013). "Currency hierarchy, liquidity preference and exchan ge rates: a Keynesian/minskyan approach", In: Congrès de I'Association Française d'Économie Polit ique Université, Bordeaux.

Dedecca, C. S. (2014). "A queda da desigualdade de renda corrente e a participação do $1 \%$ de domicílios de maior renda, 2000-2010", Revista de Economia Política, vol. 34, № 2 (135), pp. 249-265, abril-junho/2014.

De Negri, F.; Alvarenga, G. (2011). "A primarização da pauta de exportações no Brasil: ainda um dilema", In: Radar tecnologia, produção e comercio exterior, IPEA, n.13.

Dos Santos, C. H. et. al. (2015). "Por que a elasticidade-câmbio das importações é baixa no Brasil?", Texto para Discussão IPEA, n. 2046. 
Dieese. (2014). "A evolução do crédito na economia brasileira", Nota técnica número 135, Maio de 2014.

FES, Forum21, Plataforma Política Social, GT de Macro SEP (2016) Austeridade e retrocesso: Finanças públicas e política fiscal no Brasil, São Paulo.

Furtado, C. (1971). Teoria e Política do Desenvolvimento, São Paulo: Nacional.

Furtado, C. (1992). "O Subdesenvolvimento Revisitado", Economia e Sociedade, n. 1. Campinas, ago 1992.

Hoffmann, R. (2013). "Transferências de renda e desigualdade no Brasil (1995-2011)". In: Tereza Campello; M arcelo Côrtes Neri. (Org.). Programa Bolsa Família: uma década de inclusão e cidadania, Brasília: IPEA, v. 1, p. 207-216.

Hiratuka, C.; Sarti, F. (2015). "Transformações na estrutura produtiva global, desindustrialização e desenvolvimento industrial no Brasil: uma contribuição ao debate", Texto para Discussão IE/Unicamp, Campinas, n. 255, jun.

IPEA. (2013). "Duas décadas de desigualdade e pobreza no Brasil medidas pela Pnad/IBGE", Comunicados do IPEA, n 159, 01 de outubro de 2013.

Komatsu, B. K.; M enezes Filho, N. (2015). "Salário mínimo e desigualdade salarial: um estudo com densidades contrafactuais nas regiões metropolitanas brasileiras", Revista Pesquisa e Planejamento Econômico, 45 (3), .

Lewis, W. A. (1954). "Economic development with unlimited supplies of labour". The Manchester School, 22 (2): 139-191 Posteriormente republicado em AGARWALA, Amar. N. e SINGH, Sampat. P. (1964).

Medeiros, C. A. (2015). "Inserção externa, crescimento e padrões de consumo na economia brasileira", Brasilia: IPEA.

Medeiros, M.; Souza, P.; Castro, F. (2015). "A estabilidade da desigualdade de renda no Brasil, 2006 a 2012: estimativa com dados do imposto de renda e pesquisas domiciliares", . Ciênc. saúde coletiva, vol.20, n.4, pp.971-986.

M ello, G. S.; Chiliatto Leite, M V (2011). "Contração fiscal reduz juros? Uma crítica keynesianomarxista", In: IV Encontro da Associação Keynesiana Brasileira, 2011, Rio de Janeiro. Anais do IV Encontro da Associação Keynesiana Brasileira, 2011.

M esquita, M. (2014). "A política econômica do governo Dilma: A volta ao experimentalismo", In: Sob a Luz do Sol, Uma Agenda para o Brasil: A Política Econômica do Governo Lula: a volta do experimentalismo. CDPP, p. 3-15.

Nogueira, M., Infante, R.; Mussi, C. (2014). "Produtividade do trabalho do trabalho e heterogeneidade", In: DE NEGRI, F. CALVANT, L. Produtividade no Brasil: Desempenho e Determinantes, Brasília: IPEA e ABDI.

Pinto, A. (1979). "Heterogeneidade estrutural e modelo de desenvolvimento recente", In: SERRA, J. (org) América Latina - ensaios de interpretação econômica, Rio de Janeiro: Paz e Terra.

Quadros, W. (2015). "Paralisia econômica, retrocesso social e eleições", Revista Plataforma de Política Social, 21 de Janeiro de 2015.

Rezende, F. (2015). "Financial Fragility, Instability and the Brazilian Crisis: A Keynes - Minsky Godley approach", Multidisciplinary Institute for Development Strategies (Minds) Discussion Paper n. 1, 2016. 
Rossi, P.; Biancarelli, A. M. (2015). "Do industrialismo ao financismo", Revista Política Social e Desenvolvimento, pp. 14-17, 29 de janeiro de 2015.

Rossi, P. (2016). Taxa de câmbio no Brasil: teoria, institucionalidade, papel da arbitragem e da especulação, Rio de Janeiro, Editora FGV.

Serrano, F.; Summa, R. (2012). "A desaceleração rudimentar da economia brasileira desde 2011", OIKOS (Rio de Janeiro), Vol. 11, n.2.

Serrano, F.; Summa, R. (2014). Notas sobre a desaceleração rudimentar da economía brasileira. In: Sa Earp, F. ; Bastian, E. ; Modenesi, A.. (Org.). Como vai o Brasil? A Eeconomia Brasileira No Terceiro Milênio. 1ed.: , 2014.

Serrano, F.; Summa, R. (2015). "Aggregate demand and the Slowdown of Brazilian Economic Growth from 2011-2014", en CEPR, agosto de 2015.

Summa, R. (2014). "Uma nota sobre a relação entre salário mínimo e inflação no Brasil a partir de um modelo de inflação de custo e conflito distributivo", Texto para discussão Instituto de Economia UFRJ 012.

Tavares, M. C.; Serra, J. (1973). "Além da Estagnação", In: TAVARES M . C. (Org.) Da Substituição de Importações ao Capitalismo Financeiro: ensaios sobre a economia brasileira, Rio de Janeiro: Zahar Editores. 